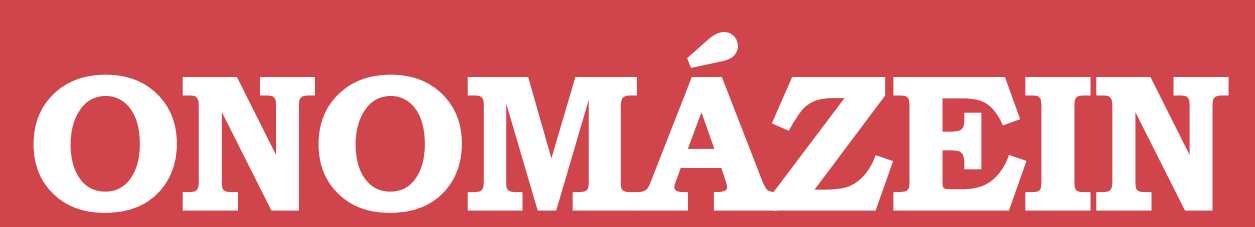

Revista semestral de lingüística, filología y traducción
PONTIFICIA UNIVERSIDAD

\title{
Análisis de la plasticidad funcional y posicional del marcador discursivo o sea (que) en una historia de vida
}

Analysis of the functional and positional flexibility of the Spanish discursive marker o sea (que) in a life story

\author{
Matías Soich \\ Consejo Nacional de Investigaciones \\ Científicas y Técnicas \\ Universidad de Buenos Aires \\ Argentina
}

\section{(C) $($ ii) $\ominus$}




\section{Resumen}

Este artículo analiza detalladamente los diversos usos que el marcador discursivo o sea (que) reviste en un texto oral del género "historia de vida" producido en la ciudad de Buenos Aires en 2013. El objetivo es clasificar y aclarar dichos usos según dos criterios: su función semántico-pragmática y su posición en la emisión. Se analizan conjuntamente seis funciones principales (aclarativo-explicativa, conclusiva, restrictiva, continuativa, reforzadora y atenuadora de cierre) y tres posiciones (inicial, media y final). Como resultado constatamos no sólo la alta frecuencia de aparición de este marcador en la oralidad, sino también la gran diversidad y plasticidad, tanto posicional como funcional, que puede adoptar a lo largo de un mismo texto. Esta versatilidad es atribuida en parte a la persistencia del sentido disyuntivo "original" de o tras un proceso de gramaticalización.

Palabras clave: marcadores discursivos; o sea (que); disyunción; gramaticalización.

\section{Abstract}

This article analyzes in detail the various uses that the Spanish discursive marker o sea (que) adopts in an oral text of the genre 'life story' produced in Buenos Aires city in 2013. The aim is to classify and clarify these uses based on two criteria: their semantic-pragmatic function and their position in the utterance. The analysis combines six main functions (explanation, conclusion, restriction, continuation, reinforcement and attenuating at closure) and three positions (initial, middle and final). The chief findings of this work are not only the high frequency of this marker in oral expression, but also the ample diversity and flexibility — concerning position as well as function - it can adopt throughout the same text. This versatility is partly attributed to the persistence of the 'original' disjunctive sense of o after a process of grammaticalization.

Keywords: discursive markers; o sea (que); disjunction; grammaticalization. 


\section{Introducción ${ }^{1}$}

En este trabajo analizamos las diversas funciones semántico-pragmáticas del marcador discursivo o sea (que) en un texto oral producido en Buenos Aires en el año 2013. El objetivo es clasificar dichas funciones lo más claramente posible, comparándolas con observaciones previas formuladas por los autores de referencia. El trabajo se organiza del siguiente modo: en lo que sigue desarrollamos sucintamente, a modo de estado del área, las características generales que definen a los marcadores del discurso (1.1), concentrándonos en los marcadores reformulativos (1.2), para luego tratar la clasificación y caracterización de o sea (que) (1.3). En la segunda sección describimos la metodología y el corpus utilizados. En la tercera sección desarrollamos y ejemplificamos los principales resultados del análisis de las apariciones de o sea (que), clasificadas según su función pragmática y posición en la emisión (subsecciones 3.1 a 3.6). Finalmente, en la sección 4 realizamos algunas observaciones a modo de conclusión.

\subsection{Los marcadores discursivos}

La mayor parte de los autores de referencia mencionados en este apartado comienzan aludiendo a la dificultad para definir y clasificar estas unidades, que suelen denominarse también "partículas discursivas", "operadores pragmáticos" o "enlaces extra-oracionales", entre otros términos². Su estudio constituye un campo cuyo crecimiento en las últimas cuatro décadas estuvo ligado especialmente al desarrollo de dos sub-disciplinas: la lingüística del texto,

1 Agradezco a Scott Schwenter, por facilitarme el acceso a su trabajo; a María Laura Pardo y Mariana Marchese, por su apoyo y sus consejos durante la revisión de este artículo; y muy especialmente a Ana María Marcovecchio, por darme el aliento necesario para presentarlo y por su gran generosidad para realizar valiosas observaciones y sugerencias. No es necesario aclarar que cualquier falencia en este trabajo me corresponde exclusivamente.

2 Respecto de la amplia variedad terminológica utilizada para referirse a lo que aquí llamamos "marcadores discursivos", Casado Velarde menciona por ejemplo las denominaciones "enlace", "conector", "nexo" y "operador discursivo" (1991: 96). Fuentes Rodríguez los Ilama "conectores pragmáticos" (1993) y registra otras denominaciones como "enlaces conjuntivos" y "ordenadores de la materia discursiva" (1996). Para un recuento documentado de las diversas denominaciones adoptadas y sus motivaciones, véase Garcés Gómez (2008: 14-17). Acerca de la delimitación de los marcadores discursivos, Degand y otros (2013) reúnen trabajos dedicados especialmente al problema de cómo diferenciar entre marcadores discursivos (discourse markers) y partículas modales (modal particles). La dificultad para clasificar gramaticalmente los marcadores puede ilustrarse con el caso de Hernández Alonso, quien, en su Gramática funcional del español (1996), sólo los menciona una vez, en el capítulo dedicado al adverbio. En el apartado sobre los modos de deixis, dice en efecto que "estos deícticos en el texto sirven de concatenadores, de elementos de enlace, de marcadores del discurso, y de factores de cohesión textual” (1996 [1984]: 639, énfasis añadido). 
para la cual el descubrimiento de los marcadores discursivos constituyó una prueba de la existencia del texto como unidad superior a la oración; y la pragmática, que encontró en los marcadores la posibilidad de estudiar inferencias que exceden el plano de la sintaxis (Portolés, 2001 [1998]: 7-9). Es por ello que, tras repasar diversos intentos de clasificar estas unidades desde un punto de vista predominantemente gramatical, Garcés Gómez concluye: "podemos considerar que nos encontramos ante una categoría pragmática, que no puede caracterizarse por los rasgos formales de las unidades que la integran, aunque puedan servir para su delimitación, sino por la función de establecer relaciones entre los enunciados" (2008: 24).

Los autores que aquí se mencionan coinciden en señalar que los marcadores discursivos comprenden una gran variedad de clases de palabras. Esto implica que en su formación interviene un proceso de gramaticalización por el cual diversas unidades léxicas (adverbios, preposiciones, conjunciones, etc.) se descategorizan como tales para recategorizarse como marcadores (Company, 2014: 16)3. La amplitud de clases de palabras que pueden formar marcadores del discurso es señalada, por ejemplo, en la Nueva gramática de la lengua española (RAE y ASALE, 2010), que aborda los marcadores en el capítulo dedicado al adverbio y el grupo adverbial, más específicamente en la subsección 30.9, "Conectores discursivos adverbiales". Allí se señala como propiedad su relativa independencia sintáctica y fónica en la oración y se afirma que la mayor parte de estos conectores "orientan la manera en que la oración o el fragmento oracional sobre el que inciden han de ser interpretados en relación con el contexto precedente o con las inferencias que de él se obtienen", ya que vinculan la oración "con el discurso en el que está inserta atendiendo especialmente a la línea argumentativa que el hablante desea seguir" (30.9.1d, énfasis original).

En el capítulo correspondiente de la Gramática descriptiva de la lengua española, Martín Zorraquino y Portolés dan la siguiente definición de los marcadores discursivos: "son unidades lingüísticas invariables, no ejercen una función sintáctica en el marco de la predicación oracional y poseen un cometido coincidente en el discurso: el de guiar, de acuerdo con sus distintas propiedades morfosintácticas, semánticas y pragmáticas, las inferencias que se realizan en la comunicación" (1999: 4057). En un trabajo posterior, Martín Zorraquino (2004) reafirma esta definición y enfatiza dos rasgos de los marcadores: su "heterogeneidad categorial" y el hecho de que pueden marcar tanto la posición del hablante respecto de un mensaje

3 Ya Bello (2002 [1847]), en el capítulo L de su Gramática, "Observaciones sobre el uso de algunos adverbios, preposiciones y conjunciones", enumera diversos casos de "la facilidad con que estas palabras se transforman unas en otras". Señala además en una nota que "son esencialmente distintos los oficios del adverbio, de la preposición, de la conjunción; la palabra que pasa de una clase a otra varía de sintaxis y aun de significado", prefigurando así los procesos de gramaticalización que dan lugar a los marcadores discursivos. 
designativo, como la relación que para él se da entre las secuencias de dicho contenido, como la interrelación hablante-oyente, de manera que su significado principal no es por sí mismo conceptual o denotativo. Del mismo parecer es Portolés (2014), quien a estos dos criterios sintáctico-morfológicos (ser palabras invariables y no ejercer función sintáctica en la predicación) añade dos criterios semánticos para seleccionar marcadores discursivos: contener diversas instrucciones polifónico-argumentativas y no modificar las condiciones de verdad de su miembro del discurso.

En un trabajo dedicado a los adverbios terminados en -mente como marcadores del discurso, Company enfatiza la autonomía predicativa de los marcadores y desarrolla esta propiedad afirmando que

pueden aparecer solos en la narración y son aislables mediante pausas; por lo mismo, carecen de función sintáctica alguna en el tramo sintagmático en que se insertan, tampoco establecen relación alguna con el verbo de la oración, no introducen participantes o argumentos en la predicación y no entablan relación semántica ni sintáctica con ningún elemento del enunciado en que aparecen, de manera que, en su gran mayoría, tienen el rasgo de omisibilidad, aunque aporten un alto significado pragmático y sean necesarios para el éxito comunicativo y eficiencia informativa del enunciado (2014: 17, énfasis original).

En su estudio sobre es decir, esto es, o sea y a saber, Casado Velarde (1991) caracteriza a los marcadores discursivos (que él denomina operadores) como formas lexicalizadas y por lo tanto invariables, que suelen ir separadas por pausas o por rasgos de entonación. Respecto del tipo de relación sintáctica que introducen, afirma que "no es una relación constitutiva del nivel de la estructuración idiomática oracional” (1991: 102). Distingue entre aquellos marcadores que pueden situarse tanto al comienzo, en el medio como al final de una explicación, y aquellos que sólo admiten situarse al comienzo — si bien, en el caso de o sea, reconoce que también puede situarse al final del enunciado (1991: 103). Desde el punto de vista pragmático, el autor señala que estos operadores sirven al hablante para controlar la interpretación de su discurso en función de diversas creencias, expectativas y normas propias de la interacción comunicativa. En este sentido, los operadores tienen la "función estructural positiva" (1991: 115) de producir discursos intertextuales o polifónicos.

Fuentes Rodríguez (1996), quien habla de "relacionantes supraoracionales", los caracteriza como elementos de relación discursiva que no tienen una función sintáctica dentro de la oración y derivan de la gramaticalización de otros elementos. Afirma que se sitúan generalmente en el margen oracional, formando un grupo entonativo aparte delimitado por pausas. Respecto de sus funciones, la autora distingue tres niveles de las relaciones supraoracionales que estos elementos articulan: interdiscursivo (mantenimiento de la relación dialógica hablante-oyente), macroestructura textual (organización de las partes de un texto) y microestructura textual (establecimiento de la relación entre dos oraciones o enunciados). 
En estos niveles, los relacionantes no sólo aportan diversos contenidos (aditivos, causativos, reformulativos, etc.), sino que también pueden cumplir funciones argumentativas.

Garcés Gómez caracteriza los marcadores discursivos como "unidades lingüísticas invariables, sin función sintáctica en el plano de la predicación oracional, que, de acuerdo con sus propiedades morfosintácticas y con sus instrucciones semánticas y pragmáticas, señalan cómo ha de interpretarse el contenido de los enunciados en relación con lo expresado previamente, con las percepciones derivadas de la situación comunicativa o con los conocimientos compartidos" (2008: 16-17). A pesar de su movilidad distribucional, sostiene que "tienden a situarse al inicio, o en un lugar próximo al comienzo del enunciado" (2008: 23).

Como puede verse, estos autores tienden a coincidir, a grandes rasgos, sobre las principales características que definen a los marcadores discursivos ${ }^{4}$. Para sintetizar lo expuesto hasta aquí, enumeramos con García Negroni (2014: 5-6) cinco propiedades que agrupan lo anotado por el resto de los autores. 1) Se trata de unidades lingüísticas invariables, pertenecientes a diversas categorías gramaticales (propiedad morfológica). 2) No ejercen función sintáctica dentro de la predicación oracional (propiedad sintáctica). 3) Se ubican generalmente en posición inicial respecto del miembro discursivo que introducen (propiedad sintáctica). 4) Están limitados por rasgos de entonación en la oralidad y por comas en la escritura (propiedad prosódica). 5) Contienen diversas instrucciones polifónico-argumentativas y, por lo tanto, su significado principal no es conceptual, sino de procesamiento (propiedad semánticopragmática). A estas agregamos, siguiendo a Portolés (2014), otra propiedad semántica: 6) no modifican las condiciones de verdad de su miembro del discurso.

Respecto de la clasificación de los marcadores, Martín Zorraquino y Portolés (1999) determinan cinco grandes grupos: estructuradores de la información, conectores, reformuladores, operadores argumentativos y marcadores conversacionales. El grupo de los reformuladores incluye los marcadores explicativos (donde los autores clasifican a o sea), los de rectificación, los de distanciamiento y los recapitulativos. Más recientemente, la Nueva gramática de la lengua española divide los marcadores ("conectores discursivos adverbiales") en doce grupos, aclarando que, de acuerdo al contexto, la clasificación de una misma locución puede variar (RAE y ASALE, 2010: 30.9.2b). En efecto, si bien o sea es clasificado allí como conector explicativo, los resultados de nuestro análisis muestran que también puede asociarse con

4 Por nombrar a otros autores, Cuenca (2013) señala con diferentes grados de detenimiento las diversas características expuestas hasta aquí, enfatizando lo difícil que resulta erigir a cualquiera de ellas como una razón necesaria y suficiente para distinguir un marcador discursivo de una partícula modal. También Urgelles-Coll (2010) apunta estas diversas características y, al igual que Company, menciona entre ellas la omisibilidad (2010: 24). 
nueve de esos doce grupos (conectores de precisión o particularización, adversativos o contra argumentativos, consecutivos e ilativos, reformuladores, ejemplificativos, rectificativos, recapitulativos, de digresión y de apoyo argumentativo).

\subsection{La reformulación}

Dadas las características de la mayor parte de los usos de o sea (que) que analizamos en este trabajo, nos concentraremos especialmente en la reformulación y en la distinción entre reformuladores parafrásticos y no parafrásticos.

Gülich y Kotschi (1983) sostienen que, desde el punto de vista de la descripción estructural, los elementos que pueden servir como marcadores de reformulación parafrástica en francés “forman una categoría bastante heterogénea” (1983: 315, traducción propia). Según los autores, los marcadores reformulativos "juegan un papel importante en la producción (interactiva) del discurso, ya que se encuentran entre los 'rastros' del trabajo de la formulación” (1983: 314, traducción propia). Esta función global de organización discursiva propia de los marcadores no se contrapone a sus rasgos argumentativos, sino que ambas son complementarias. Los autores consideran que la actividad parafrástica tiene como nota esencial el carácter interactivo: se trata de un medio que sirve para resolver diferentes tipos de problemas comunicativos ligados a la organización textual, la comprensión y recepción y la interacción entre hablantes.

Dicho carácter interactivo es, desde ya, inseparable de la diversidad de voces y puntos de vista5, aunque no por ello excluye la posibilidad de que uno de los hablantes, precisamente quien reformula, asuma un control parcial de la situación comunicativa. Fuentes Rodríguez sostiene que la reformulación es "una actividad enunciativa que muestra el control de la comunicación por parte del hablante” (1993: 173). En el mismo sentido, García Negroni señala que las operaciones de reformulación implican, por parte del locutor, la "voluntad de ejercer un cierto control metadiscursivo de la producción del sentido" (2009: 48), a través de una referencia anafórica que retoma elementos previos para modificar su sentido con fines pragmáticos 6 .

5 Dado que sus dos miembros expresan o acusan, más o menos marcadamente, diferentes puntos de vista, "todas las reformulaciones son intrínsecamente polifónicas" (Murillo 2009: 149).

6 Cubo de Severino destaca la alteración del ritmo discursivo con fines comunicativos: Ios reformuladores "detienen el ritmo, llevan a inferencias retroactivas locales que buscan la fuente de información en el discurso previo y agregan otros valores contextuales que suponen una reinterpretación de lo anterior, que queda explicado o reconsiderado en la búsqueda de una reformulación que se considere eficaz, comunicacionalmente feliz" (2014: 348). 
Al distinguir entre marcadores de reformulación parafrástica y no parafrástica, esta autora apunta como nota básica del primer tipo el plantear la equivalencia entre dos formulaciones con el objetivo de aclarar, ampliar o reducir la primera a través de la segunda. Para García Negroni, las operaciones de reformulación parafrástica no implican necesariamente el uso de marcadores como es decir u o sea, ya que pueden llevarse a cabo mediante otros procedimientos léxicos y sintácticos (2009: 48). Por el contrario, las operaciones de reformulación no parafrástica —en las que no hay equivalencia entre las dos formulaciones - sí requieren un marcador que indique explícitamente la naturaleza de la reformulación’. García Negroni distingue cuatro funciones principales de la reformulación no parafrástica. Respecto de lo dicho en el miembro anterior, esta puede servir para recapitularlo, destacando lo que se considera esencial; para reconsiderarlo, confirmando o modificando la dirección argumentativa sostenida hasta ese momento; para distanciarse de lo dicho, atenuando la fuerza que le fuera concedida; y finalmente para invalidarlo, pudiendo dar pie a una corrección ${ }^{8}$. La autora propone reunir estas operaciones en una gradación continua que abarca los distintos grados de distanciamiento articulados por el marcador, desde la reformulación parafrástica a la no parafrástica9. Ilustramos este continuo en el esquema 1.

\subsection{El marcador discursivo o sea (que)}

Moliner (2001) apunta dos funciones de la expresión o sea: una conclusiva, "generalmente en tono de crítica", asimilable a la expresión esto es; y otra aclarativa, que permite explicar mejor "algo que se acaba de decir". Las mismas funciones se reiteran en las sendas entradas de o sea del Diccionario de partículas discursivas del español (Briz y otros, 2008). La primera entrada

7 Con un criterio diferente, al comienzo de su trabajo Gülich y Kotschi afirman que toda reformulación precisa de algún tipo de marcador (marqueur) explícito, si bien no necesariamente debe ser una unidad o grupo léxico (1983: 305). Más adelante, precisan esta afirmación explicando que la presencia explícita de un marcador de reformulación es tanto más necesaria cuanto menor es el grado de equivalencia semántica entre las dos expresiones en cuestión: "la función de los MRP [marcadores de reformulación parafrástica], a saber, el establecimiento de una relación parafrástica, (...) deviene más y más dominante a medida que la equivalencia semántica disminuye” (1983: 326, traducción propia).

8 Estas cuatro funciones se encuentran ya descriptas en Fuentes Rodríguez (1993: 175). Por otra parte, si bien articulan su trabajo sobre la diferencia entre la reformulación semántico-pragmática y la discursiva, también López Serena y Loureda (2013) distinguen entre reformulación parafrástica y no parafrástica de manera muy similar a la explicada en este apartado.

9 Gülich y Kotschi (1983) sostienen también este criterio gradualista: "la equivalencia semántica aparece bajo la forma de una gradación diferenciada, que se extiende entre dos polos extremos. (...) que se caracterizan respectivamente por un caso de equivalencia máxima y un caso de equivalencia mínima" (1983: 325, traducción propia). 


\section{ESQUEMA 1}

Continuo de la reformulación (sobre la base de García Negroni (2009: 51))

\begin{tabular}{|c|c|c|c|c|}
\hline & Recapitulación & Reconsideración & Distanciamiento & \\
\hline Repetición & $\begin{array}{c}\text { Condensación del } \\
\text { movimiento } \\
\text { discursivo previo }\end{array}$ & $\begin{array}{l}\text { Introducción de un nuevo } \\
\text { punto de vista que puede } \\
\text { reforzar o no lo anterior }\end{array}$ & $\begin{array}{l}\text { La reformulación } \\
\text { concierne a lo dicho } \\
\text { de modo más total }\end{array}$ & Invalidación \\
\hline
\end{tabular}

refiere a la función conclusiva, según la cual o sea (que) introduce una conclusión que frecuentemente "constituye una valoración de la cual cabe inferir o interpretar algo diferente, incluso a veces opuesto" a lo esperado. La segunda refiere a la función aclarativo-explicativa de o sea. El DPDE reúne aquí usos tales como marcar una equivalencia real o pretendida, ilustrar mediante un ejemplo y rectificar lo dicho anteriormente, señalando a propósito de esto último que "con frecuencia, la rectificación añade un matiz de atenuación, especialmente en situaciones problemáticas en las que, por ejemplo, la imagen propia o ajena puede quedar afectada".

Podemos observar que el primer sentido general de o sea, como marcador discursivo de conclusión, no entraría entre los marcadores típicos de reformulación, mientras que sí lo haría en tanto introductor de una aclaración o explicación.

En un estudio dedicado específicamente al uso de o sea en el español peninsular oral, Schwenter (1996) presenta un cuadro más complejo de estas dos funciones. Tras señalar las características formales de o sea como marcador, el autor distingue entre usos conectivos y usos epistémicos: Ios primeros indican cuál es la relación entre dos partes del discurso, mientras que los segundos indican la actitud y el nivel de compromiso del hablante respecto de lo que dice (1996: 855). También sostiene que hay usos combinados de estos dos tipos. Los usos conectivos de o sea comprenden las dos funciones que mencionamos antes: por un lado, tenemos la reformulación, la explicación y clarificación de lo que precede; por el otro, en el caso particular de o sea que, Schwenter interpreta un uso conectivo especializado en introducir una conclusión o consecuencia (1996: 863) ${ }^{10}$. En cuanto a los usos epistémicos, el autor des-

10 Otros usos conectivos de o sea descriptos por Schwenter incluyen: marcar el límite entre las acciones narradas y el trasfondo en la narrativa oral; señalar la necesidad de dar más información tras una respuesta breve del tipo sí/no; y como elemento de cortesía que mitiga la fuerza de una orden. 
cribe o sea como expletivo o muletilla que "sostiene" las vacilaciones durante la producción del discurso; cuando ocurre en posición final, en cambio, afirma que sirve para preservar la imagen positiva del hablante, al permitir intervenciones o cuestionamientos del interlocutor respecto de algo que se acaba de decir y que puede resultar polémico o controversial. En términos generales, Schwenter atribuye esta atenuación del compromiso con lo que se acaba de decir a la persistencia del sentido del modo subjuntivo, que permitiría incrementar el contenido epistémico de las emisiones - aun cuando, por formar parte de un marcador gramaticalizado, el verbo ser en o sea no conserve su sentido "pleno" (1996: 868).

Schwenter no es el único autor que señala la asociación entre la presencia de que y la función de introducir una conclusión o consecuencia. Hemos visto que el DPDE desarrolla la función explicativa en la entrada o sea (sin que), mientras que la función conclusiva queda reservada para la entrada o sea (que). Casado Velarde sostiene que es decir que y o sea que agregan, respecto de las mismas formas sin que, "un rasgo de 'consecuencia'” (1991: 108). El análisis de Murillo, quien diferencia cuidadosamente las distintas maneras en las que que puede seguir a un marcador de reformulación explicativa (conjunción completiva, que soldador, pronombre relativo, etc.), arroja una casi total prevalencia de las funciones de conclusión y consecuencia para o sea seguido de que (2015: 176). Por su parte, Rodríguez Ramalle (2014b) retoma los estudios de Casado Velarde, Schwenter y Murillo, y relaciona la presencia de la conjunción que - cuando se presenta en oraciones independientes, con consecutivos ilativos o con marcadores reformulativos - con la referencia a diferentes fuentes de la información que permiten inferir premisas o conclusiones ajenas al orden del discurso previo. El planteamiento de esta autora se apoya en los estudios anteriores, que asocian la presencia de que con la función conclusiva, agregando la posibilidad de que esta conjunción exprese un tipo de evidencialidad basado en fuentes diferentes de la información. Señala también que la forma o sea que, a diferencia de otros marcadores, tiene la posibilidad peculiar de introducir preguntas y órdenes y de aparecer con actos desiderativos y expresivos (2014b: 133).

En lo expuesto hasta aquí podemos empezar a apreciar la amplia variedad de funciones que este marcador puede adoptar. Fuentes Rodríguez (1993; 1996) clasifica a o sea como un marcador parafrástico de tipo explicativo, aunque sostiene que - junto a otros marcadores "genéricos" como es decir y bueno- también puede aparecer con diversos valores reformulativos no parafrásticos como: resumen, reconsideración, final o conclusión de una serie, ejemplificación, entre otros. En un completo estudio contrastivo, Murillo (2009) identifica a o sea como marcador de procesos discursivos de desarrollo de la forma lógica, de formación de explicaturas, de recuperación de premisas implicadas y de recuperación de conclusiones implicadas, así como también registra usos modales de énfasis asociados a la conclusión y usos reparadores, ligados a reformulaciones no planificadas de la conversación. Pons Bordería afirma de o sea que se trata "del marcador con un mayor número de distribuciones, del que está menos restringido por el registro, del más difundido entre los hablantes de español 
y (...) del que tiene una mayor capacidad para desarrollar polisemias" (2014: 989). Este autor explicita cierto nivel de consenso alcanzado en torno a los principales valores que asume o sea en la actualidad, sintetizando su versatilidad funcional en seis valores que reaparecerán en nuestro análisis: como reformulador parafrástico, como reformulador no parafrástico, conclusivo, con valor modal de refuerzo, con valor modal de atenuación y con valor formulativo (Pons Bordería, 2014: 988-989).

La versatilidad de o sea está ligada, lógicamente, a la amplitud funcional que caracteriza a la propia reformulación. A propósito de esta Cuenca sostiene que "no es una función del discurso simple. Debería ser considerada una categoría semántica compleja que abarca desde la estricta paráfrasis hasta otros valores como la especificación, la explicación, el resumen o la denominación, e incluso sentidos no parafrásticos como la implicación, la conclusión y el contraste" (2003: 1073, traducción propia). Esta variedad de sentidos de la reformulación ha sido graficada mediante el esquema 1.

Respecto del origen de o sea, Martín Zorraquino describe de modo general a los marcadores como resultado de un proceso de gramaticalización y da como ejemplos las locuciones adverbiales, conjuntivas "u otros tipos de signos complejos gramaticalizados", entre los cuales menciona precisamente a este marcador (2004: 54). Como vimos antes, Schwenter remarca la persistencia del subjuntivo a través del proceso de gramaticalización de o sea, aunque no dice nada sobre el sentido disyuntivo aportado por el conector o. Espinosa Elorza (quien por otra parte remite al trabajo de Schwenter) resalta en cambio el papel de la disyunción: "O sea está relacionado con la estructura disyuntiva que remite a SIT... SIT, traducida con las formas correspondientes del verbo romance como sea... sea y combinada con la disyuntiva más general con o" (2010: 166-167). Casado Velarde afirma que la forma o sea aparece como marcador de explicación o reformulación en el siglo XVIII y que "hereda, en parte, el valor de las conjunciones latinas sive y vel (con la misma raíz de velle), con el significado de 'o lo que es lo mismo', 'o, si se quiere', 'o (u)', frente al significado disyuntivo de carácter alternativo, continuador de la función de aut latino ('o bien')” (1996: 325). El autor señala además que la forma no lexicalizada que da origen a este marcador es "(sea) X o sea Y".

En su estudio sobre los procesos de (des)gramaticalización y subjetivización en el pasaje de verbos a marcadores discursivos, Company analiza o sea como aquel marcador que surge a partir del verbo estativo ser. El análisis cuantitativo del corpus estudiado por la autora arroja que este marcador es el segundo en términos de frecuencia de uso, sólo por debajo del derivado del verbo estar (2004: 55). En consonancia con Schwenter, Company sostiene que "en todos los casos [de pasaje de verbo a marcador] el nuevo significado discursivo-pragmático está conceptual y estructuralmente relacionado con el significado conservador referencial etimológico del verbo base" (2004: 35). Sin embargo, los ejemplos que proporciona, tanto del uso pleno como del uso pragmático-subjetivo de o sea, no acusan la persistencia de dicho sig- 
nificado conservador, particularmente en lo que hace al sentido disyuntivo. En la subsección 3.4 y en las observaciones finales intentaremos subrayar dicha persistencia.

\section{Metodología y corpus 2.1. Metodología}

El estudio cuyos resultados se presentan en este trabajo se desprende de una investigación doctoral más amplia ${ }^{11}$, cuyo propósito central es examinar, desde el marco del análisis crítico del discurso (Fairclough, 1992; Van Dijk, 1999; Pardo Abril, 2007; Pardo, 2011), la construcción de representaciones discursivas sobre la identidad de género en historias de vida de personas trans $^{12}$. Esto supone la aplicación del método sincrónico-diacrónico de análisis lingüístico de textos (Pardo, 2011)13, en cuyo trascurso advertimos una elevada frecuencia de uso de operadores pragmáticos entre los que destacaban o sea y o sea que ${ }^{14}$. Si bien en un primer momento este hecho - quizás en cierta medida "naturalizado" - no había despertado nuestra atención, posteriormente consideramos que la reiterada presencia de diversos operadores, sobre todo aquellos ubicados en los márgenes de las estructuras oracionales, era significativa para orientar el análisis general de las historias de vida, dado que estos elementos, "desprendidos" de la órbita de la predicación, revelan el posicionamiento discursivo del locutor frente a lo que enuncia. Adoptamos entonces la hipótesis de que aquellos operadores o marcadores pragmá-

11 “Los 'devenires' y la identidad de género: hacia un análisis lingüístico-crítico y conceptual de la construcción de representaciones discursivas sobre la propia identidad de género en personas trans de la Ciudad de Buenos Aires (2013-2015)", Facultad de Filosofía y Letras de la Universidad de Buenos Aires. Proyecto dirigido por María Laura Pardo y co-dirigido por Mónica Cragnolini y Ilevado a cabo a través de una beca doctoral otorgada por el Consejo Nacional de Investigaciones Científicas y Técnicas de Argentina.

12 La expresión persona trans abarca a todas aquellas personas que no se identifican con el género (masculino o femenino) según el cual fueron criadas socialmente. Por ejemplo, se llama varón trans a aquella persona que, habiendo sido criada como mujer en función de su genitalidad, se identifica luego con el género masculino -independientemente de si decide o no realizar algún tipo de intervención, quirúrgica o de otra índole, sobre su cuerpo.

13 Este método de análisis, desarrollado por Pardo, es a su vez una teoría sobre el lenguaje. Puede ser aplicado a textos orales y escritos y su aporte fundamental consiste en que permite visualizar, de modo inductivo, las relaciones complejas que se dan entre la práctica textual y la práctica social (concebidas a partir del modelo de Fairclough (1992)) mediante la reconstrucción de las diferentes categorías gramaticalizadas y semántico-discursivas cuyo despliegue constituye el devenir de cada texto.

14 La denominación "operador pragmático" refiere a una categoría de análisis propia del método sincrónico-diacrónico, bajo la cual pueden clasificarse, entre otros tipos de unidades, los marcadores discursivos. 
ticos generalmente situados al comienzo de la emisión tendrían una especial relevancia para la interpretación de la emisión en su conjunto. Por este motivo, aunque el objetivo específico de este trabajo fue analizar descriptivamente los diversos empleos que el marcador o sea (que) presenta en el corpus seleccionado, dicho objetivo se enmarca en uno más general: comprender con mayor profundidad el poder que operadores pragmáticos como o sea (que), muy frecuentes en corpus orales como los que trabajamos, tienen para guiar la interpretación de las emisiones.

Lo que presentamos aquí es un análisis de caso. Los pasos que hemos seguido fueron los siguientes:

1. En primer lugar procedimos a detectar todas las apariciones de o sea (que) en el corpus y a sistematizarlas según su afinidad funcional y de sentido. Para diferenciar entre las diversas funciones semántico-pragmáticas, nos valimos de operaciones de conmutación con otros marcadores discursivos (Portolés, 2001 [1998]) y de paráfrasis que permitieron comprobar el sentido del marcador en cada caso. Si bien la clasificación tomó como punto de partida la caracterización general de o sea (que) brindada por Moliner (2001) y el DPDE, las pruebas de paráfrasis y conmutación tuvieron en esta etapa un carácter preliminar.

2. Una vez obtenido un agrupamiento funcional provisorio de las apariciones de o sea (que), procedimos a revisarlo de acuerdo con las observaciones de los autores de referencia, lo que permitió realizar una clasificación más precisa de las funciones de este marcador.

3. Hasta ese momento del análisis, no consideramos como criterio la presencia/ausencia de la conjunción que. Incorporar esta variable morfosintáctica permitió establecer una correlación general entre las funciones semántico-pragmáticas encontradas y la ausencia/presencia de que - no obstante, como veremos en el desarrollo del trabajo, constatamos algunos casos en los que la misma función discursiva puede ser expresada tanto por o sea como por o sea que.

4. Como último paso, se incorporó al estudio el criterio de la posición (inicial, media o final) que o sea (que) ocupaba en cada emisión. Así, pudimos observar que (salvando el caso particular de la función atenuadora de cierre) ninguna posición apareció unívocamente ligada a una función específica.

En términos generales, los resultados de este análisis de caso evidencian una notable amplitud de usos de o sea (que). La mayor parte de estos usos se encontraba reflejada en la bibliografía consultada. Los resultados fueron resumidos en tablas de tipo cuantitativo, que registran la cantidad de apariciones de cada marcador según los diversos criterios adoptados. Dado que nuestro interés principal se centra en las funciones semántico-pragmáticas, los datos cuantitativos requirieron ser interpretados cualitativamente. En efecto, apoyándonos fundamentalmente en nociones de la teoría de la argumentación (Anscombre y Ducrot, 1983) para describir los datos, iniciamos una indagación sobre las particularidades de este marcador del 
discurso a partir de las clasificaciones establecidas. Por otra parte, asumiendo que los estudios sobre pragmaticalización también contribuyen a mejorar las explicaciones sobre estas partículas - esto es, cómo determinadas piezas léxicas pueden convertirse en marcadores del discurso como resultado de un proceso de subjetivización — hemos tomado para la descripción algunos aportes de la lingüística cognitiva, de corte funcionalista (Traugott, 2007; Company, 2014).

\subsection{Corpus}

El corpus analizado consiste en una historia de vida (Linde, 1993) registrada en junio de 2013 en el barrio céntrico de Almagro, que integra un corpus más amplio reunido en la Ciudad de Buenos Aires entre 2013 y 2015. Se trata de relatos orales centrados en la trayectoria de vida de personas trans, con intervenciones esporádicas de parte del entrevistador destinadas a sostener el ritmo del relato, pero evitando incidir en su contenido. Hemos realizado el registro de las historias de vida en audio mediante un grabador y, posteriormente, las hemos transcripto siguiendo pautas especiales ${ }^{15}$. En este caso, quien narra su historia es Marcos (nombre ficticio), un varón trans de 35 años. La grabación dura una hora y la transcripción resultante comprende 668 emisiones - aproximadamente 8.400 palabras ${ }^{16}$. Seleccionamos esta historia debido a que, en comparación con otras de mayor extensión, el marcador o sea (que) presentaba una mayor frecuencia de apariciones.

\section{Resultados del análisis del marcador o sea (que)}

El análisis cuantitativo arrojó 73 apariciones de o sea, en todos los casos utilizado como marcador discursivo (no se registró ningún uso pleno). Tanto el análisis como la presentación de los resultados siguen dos criterios. En primer lugar, la presencia o ausencia de que. En segun-

15 Las pautas que aparecen en los ejemplos en este trabajo son las siguientes. Los dos puntos indican el alargamiento de un sonido. Las comas, barras y barras dobles indican pausas breves, medias y largas (La verdad, es que:.:/ no::// no me acuerdo). Los círculos en superíndice indican descenso del volumen (me dijo ${ }^{\circ}$ que no ${ }^{\circ}$ ), mientras que las mayúsculas indican aumento del volumen (me dijo QUE NO). Las palabras o frases subrayadas indican un incremento de la velocidad al hablar (pero a mí igual, no me importa). El signo “=” indica interrupción o superposición de voces. Los comentarios del investigador van entre paréntesis "()", mientras que la información contextual y cotextual necesaria para comprender los ejemplos se repone entre corchetes "[ ]".

16 Siguiendo a Pardo (2011) utilizamos como unidad mínima de análisis lingüístico la emisión, cuya determinación, en el caso de la transcripción a partir de la oralidad, implica combinar criterios estructurales (una emisión es la concreción de un tema y un rema) y prosódicos (una emisión va de pausa larga a pausa larga, siendo su final usualmente indicado por una entonación descendente). 
do lugar, la posición que o sea ocupa en cada caso en la emisión (inicial, media o final). Los resultados, en términos cuantitativos, se presentan en la tabla 1.

\section{TABLA 1}

Cantidad de apariciones de o sea (que) según su posición en la emisión

\begin{tabular}{ccccc} 
& $\begin{array}{c}\text { POSICIÓN } \\
\text { INICIAL }\end{array}$ & $\begin{array}{c}\text { POSICIÓN } \\
\text { MEDIA }\end{array}$ & $\begin{array}{c}\text { POSICIÓN } \\
\text { FINAL }\end{array}$ & TOTAL \\
\hline O sea & 20 & 33 & 8 & $\begin{array}{c}61 \\
(83 \%)\end{array}$ \\
\hline 0 sea que & 6 & 5 & 1 & $\begin{array}{c}12 \\
(17 \%)\end{array}$ \\
\hline TOTAL & $\begin{array}{c}26 \\
(36 \%)\end{array}$ & $\begin{array}{c}38 \\
(52 \%)\end{array}$ & $\begin{array}{c}9 \\
(12 \%)\end{array}$ & $\begin{array}{c}73 \\
(100 \%)\end{array}$ \\
\hline
\end{tabular}

A partir de esto podemos observar, además de la evidente mayor frecuencia de o sea respecto de o sea que, la prevalencia de la posición media (si bien en el caso de o sea que predomina por un solo caso la posición inicial). Este dato parecería contradecir la caracterización de los marcadores como elementos que tienden a ubicarse en posición inicial respecto del miembro que introducen. Sin embargo, vimos que o sea aparece caracterizado como uno de los marcadores más plásticos en relación a sus posibilidades de desplazamiento, pudiendo ubicarse al principio, en el medio o al final de una emisión, e incluso entre los componentes de una cláusula (Schwenter, 1996: 858). En un estudio contrastivo de o sea respecto de sus traducciones al inglés that is (to say) e in other words, Murillo lo describe como "el marcador español con movilidad más alta" (2009: 154) y concluye que, respecto de sus contrapartes en inglés, "presenta cierta versatilidad con respecto a su posición" (2009: 158). Esta plasticidad será confirmada en los diversos ejemplos de nuestro corpus. Por lo demás, todos los rasgos de los marcadores discursivos listados en la subsección 1.1 se comprobaron en nuestro análisis.

Ahora bien, como puede suponerse, la posición de este marcador no es indiferente respecto de la función pragmática que desempeña en cada caso. Por ello, la Tabla 1, formulada en términos puramente cuantitativos, debe ser complementada con el resultado del análisis cualitativo de las diversas funciones pragmáticas registradas para o sea (que). Estos resultados se muestran en la tabla 2, desarrollada en las subsecciones siguientes. En cada una, siempre que sea posible, distinguiremos los resultados obtenidos para o sea y o sea que. Adelantamos aquí las principales funciones encontradas:

1. Una función aclarativo-explicativa, que puede involucrar una reformulación parafrástica o no parafrástica (de aquí en más RP y RNP respectivamente). 
2. Una función conclusiva, de introducción de una consecuencia.

3. Una función que llamamos restrictiva, ligada a algunas de las clases de RNP descritas por García Negroni, pero que señalamos aparte por conservar una relación más cercana con el sentido disyuntivo del conector 0 .

4. Una función que llamamos continuativa, de "sostén" durante las vacilaciones.

5. Una función reforzadora.

6. Una función atenuadora de cierre, propia de la posición final, cuyo objetivo es preservar la imagen del hablante.

\section{TABLA 2}

Apariciones de o sea (que) desglosadas según su función pragmática

\begin{tabular}{|c|c|c|c|}
\hline & POSICIÓN INICIAL & POSICIÓN MEDIA & POSICIÓN FINAL \\
\hline O sea & $\begin{array}{c}\text { Aclarativo-explicativa RNP: } 11 \\
\text { Restrictiva: } 4 \\
\text { Continuativa: } 2 \\
\text { Aclarativo-explicativa RP: } 1 \\
\text { Conclusiva: } 1 \\
\text { Anacolutos: } 1\end{array}$ & $\begin{array}{c}\text { Aclarativo-explicativa RNP: } 20 \\
\text { Conclusiva: } 4 \\
\text { Restrictiva: } 4 \\
\text { Aclarativo-explicativa RP: } 3 \\
\text { Continuativa: } 1 \\
\text { Reforzadora: } 1\end{array}$ & $\begin{array}{c}\text { Atenuadora de cierre: } 5 \\
\text { Anacolutos: } 3\end{array}$ \\
\hline O sea que & $\begin{array}{l}\text { Conclusiva: } 5 \\
\text { Aclarativo-explicativa RP: } 1\end{array}$ & Conclusiva: 5 & Atenuadora de cierre: 1 \\
\hline TOTAL & 26 & 38 & 9 \\
\hline
\end{tabular}

\subsection{Función aclarativo-explicativa: la reformulación no parafrástica}

\section{0 sea}

Ya sea en posición inicial o media, la función más frecuentemente asumida por o sea es la reformulación no parafrástica con sentido aclarativo-explicativo. Esta registró 11 casos en posición inicial y 20 en posición media. En todos los casos, este marcador permite retomar lo dicho inmediatamente antes para proporcionar nueva información que lo clarifica. Al tratarse de una RNP, la información nueva introducida por o sea no es equivalente a la ya transmitida, sino que se sitúa en otro nivel —usualmente inferior-de generalidad (ejemplo 1).

(1) Como que, a partir de, a partir de ahí [de estar en pareja con una persona trans] mi vida fue como en declive. $\mathbf{0}$ sea fue cada, cada vez más, más difícil, el peso de ser trans fue como, mucho más, mucho más fuerte. 
$\left(\mathbf{I}^{\prime}\right) \approx$ Como que, a partir de, a partir de ahí mi vida fue como en declive. Es decir, fue cada, cada vez más, más difícil, el peso de ser trans fue como, mucho más, mucho más fuerte.

$\left(I^{\prime \prime}\right) \approx$ Como que, a partir de, a partir de ahí mi vida fue como en declive. Digo que fue en declive porque fue cada, cada vez más, más difícil, el peso de ser trans fue como, mucho más, mucho más fuerte.

En el ejemplo 1, o sea en posición inicial introduce la información nueva (expresada mediante una metáfora) de que "el peso de ser trans fue mucho más fuerte", como forma de explicar la afirmación anterior (metafóricamente coherente) de que "a partir de ahí mi vida fue como en declive". Esta función aclarativo-explicativa puede testearse conmutando o sea por es decir (expresión más natural en el rioplatense oral que esto es, indicada por Moliner para esta función de o sea) (ejemplo I’). A su vez, proponemos que el matiz específicamente explicativo también puede testearse mediante una paráfrasis especial "reflexiva", mediante la cual se explicita la meta comunicativa del hablante respecto de su propio decir: digo X... porque... (ejemplo I").

El ejemplo 2 muestra que la RNP con sentido aclarativo-explicativo puede aparecer en posición inicial y media en una misma emisión:

(2) Nunca me pude como, establecer del todo en:.:, como un varón, macho, trans. 0 sea siempre estoy como cuestionándome, constantemente, eh, mi sexualidad, y mi:., mi genitalidad, o sea, nunca me, nunca me puedo como.:. ni encasillar ni quedarme quieto con los pensamientos ${ }^{17}$.

$\left(2^{\prime}\right) \approx$ Nunca me pude como, establecer del todo en:.; como un varón, macho, trans. Es decir, siempre estoy como cuestionándome, constantemente, eh, mi sexualidad, y mi:.., mi genitalidad, es decir, nunca me, nunca me puedo como:.., ni encasillar ni quedarme quieto con los pensamientos.

$\left(2^{\prime \prime}\right) \approx$ Nunca me pude como, establecer del todo en:.:, como un varón, macho, trans. Digo que nunca me pude establecer del todo como un varón, macho, trans porque siempre estoy como cuestionándome, constantemente, eh, mi sexualidad, y mi:.:, mi genitalidad, es decir, nunca me, nunca me puedo como:., ni encasillar ni quedarme quieto con los pensamientos.

Podemos observar en 2" que, mientras la posición inicial de o sea admite una paráfrasis "reflexiva", la segunda aparición en posición media no lo hace. Esto se debe a que la prime-

17 En este y todos los ejemplos, marcamos en negrita no solamente o sea (que), sino también las pausas que indican su entorno melódico. 
ra aparición de o sea tiene un matiz más explicativo — no es obvio que la información que introduce ("estar siempre cuestionando la propia sexualidad”) posea la misma orientación argumentativa que la información anterior ("no poder establecerse del todo como un varón o macho trans"). Mientras que, por su parte, la segunda aparición de o sea, si bien también introduce una RNP, presenta información ("no poder encasillarse ni quedarse quieto con los pensamientos”) más evidentemente inferible de lo anterior ("estar siempre cuestionándose").

Los ejemplos que siguen ilustran otros aspectos de la función aclarativo-explicativa no parafrástica de o sea en las posiciones inicial y media. Todos ellos admiten paráfrasis con es decir. En los ejemplos 3, 4, 5 y 6, o sea introduce, con distintos niveles de complejidad semántica y morfológica, una especificación del elemento anterior. Se trata de información nueva con un nivel de generalidad inferior respecto de lo dicho anteriormente. Así, en (3) “de los nervios, de angustia, de todo" se introduce como una especificación de "me enfermé"; en (4) "capacitación de empleo" especifica a "empleo"; en (5) "desinteresado" especifica a "amor puro" y en (6) "pasamos por la violencia de él y tomamos caminos bastante complicados" especifica a "cosas muy difíciles (...) por tener el mismo padre". En el ejemplo 7 o sea tiene una función similar, pero la especificación adquiere un matiz más marcado de ejemplificación: Ios abrazos aparecen como un ejemplo de contacto físico.

(3) Fue, fue bastante duro y:: yo me enfermé. 0 sea, ahí me, me enfermé de, de los nervios, de angustia, de todo.

(4) Es, empleo, o sea, es capacitación de empleo para personas trans.

(5) El amor, puro, o sea, desinteresado, es el que más me mueve.

(6) Nos han pasado cosas muy difíciles a ambos [Marcos y su hermano] por tener el mismo padre, o sea, ambos pasamos por la violencia de él y tomamos caminos como bastante complicados.

(7) Eh, yo por ejemplo, eh// me gusta:: el contacto físico, o sea los abrazos, eh, el decir "te amo" constantemente, no sé, preocuparme por mis amigos, o sea...

Un caso particular de esta función lo constituye la repetición seguida de o sea en una misma emisión. A pesar de calificar el empleo repetido de esta partícula como un "tic lingüístico", el DPDE admite que "puede que la repetición de varios o sea seguidos mantenga su valor explicativo o de precisión informativa" (Briz y otros, 2008). Tal es el caso en el ejemplo 8, donde la repetición de o sea — que al igual que en los ejemplos anteriores admite paráfrasis con es decir - introduce información aclaratoria en un grado creciente de especificidad: "me llama" a partir de "vive", "con mi nombre" a partir de "me llama". 
(8) [Mi abuela] Vive y, o sea, me llama, o sea con mi nombre, me respeta $(. . .)^{18}$.

Por otra parte, esta historia de vida ofrece ejemplos de o sea que corresponden a tres momentos diferentes del continuo de la reformulación propuesto por García Negroni (ver esquema 1). En el ejemplo 9, o sea en posición inicial introduce una recapitulación que condensa los significados anteriores ("para mí fue muy dura la recuperación”, "me dolía muchísimo”, etc.) en el enunciado "todo el post operatorio fue cuestionarme, por el dolor, si valía la pena”.

(9) Fue muy:., muy dura la recuperación [de la mastectomía], para mí fue muy difícil la recuperación, me dolía muchísimo, era como “Ay, por qué hice esto”, tipo... (Suspira) “¿Tenía la necesidad de..., de hacer esto?”, bueno. $\mathbf{O}$ sea, me pasé por, todo el post operatorio fue cuestionarme, por el dolor, si valía la pena.

(9) $\approx$ Es decir/ en resumen, me pasé por, todo el post operatorio fue cuestionarme, por el dolor, si valía la pena ${ }^{19}$.

En el ejemplo 10, o sea en posición inicial introduce en cambio una reconsideración de todo lo narrado, a partir de la cual el hablante refuerza la idea de que "nos terminaban echando... mucho más” (el adverbio todavía apunta en este sentido reforzador).

(10)Ella [la pareja de Marcos] también tenía otros [documentos], ella falseaba sus documentos pero alquilábamos lugares amueblados que eran muy costosos y nos terminaban echando, cuando se enteraban que [ella] era, transexual. Y mucho más ligado a la prostitución. $\mathbf{O}$ sea mucho más todavíaª.

18 Se refiere al nombre que corresponde a su identidad de género sentida (Marcos), por contraposición al nombre que le fue asignado al nacer. La Ley de Identidad de Género argentina, sancionada en 2012 y basada en los Principios de Yogyakarta de 2007, establece en su artículo 12 sobre Trato digno que "deberá respetarse la identidad de género adoptada por las personas, en especial por niñas, niños y adolescentes, que utilicen un nombre de pila distinto al consignado en su documento nacional de identidad” (Ley de Identidad de Género, 2012).

19 Tanto aquí como en ( $\left.10^{\prime}\right)$ y ( $\left(\mathrm{I}^{\prime}\right)$ ), las paráfrasis propuestas para testear el sentido de o sea incluyen primero la expresión es decir, propia de la función aclarativo-explicativa, seguida por marcadores que García Negroni (2009: 51) indica como prototípicos de diversos modos de RNP.

20 En Argentina, la mayoría de las mujeres trans (travestis y transexuales) se ve obligada a recurrir a la prostitución como forma de subsistencia, debido a la expulsión temprana del núcleo familiar y a la negativa social a contratarlas en otros empleos formales e informales. Un relevamiento realizado en 2004-2005 entre mujeres trans de la Ciudad de Buenos Aires y diversas localidades de la provincia homónima arrojó, por ejemplo, que el $79 \%$ de las entrevistadas se dedicaba a la prostitución (Berkins y Fernández, 2005). A pesar de ciertas mejoras ligadas a la sanción de leyes de cupo laboral trans, la creación de cooperativas de trabajo y la capacitación laboral desde el Estado, esta tendencia sigue siendo dominante hoy, a cuatro años de la sanción de la Ley de Identidad de Género. 
$\left(10^{\prime}\right) \approx$ Es decir/ de hecho, mucho más todavía.

Finalmente, en el ejemplo 11, o sea en posición media introduce una invalidación que permite corregir lo dicho inmediatamente antes (no se trata de una hermana, sino de varias).

(11)Eh::// digo que nací gracias como a la benevolencia de las mujeres porque/ a mi madre la cuidaron mi abuela, mi madrina, su hermana, o sea sus hermanas (...)

(II') ₹ a mi madre la cuidaron mi abuela, mi madrina, su hermana, es decir/ no, sus herma$\operatorname{nas}(\ldots)$

\section{O sea que}

Como puede observarse en lo anterior, todos los ejemplos ofrecidos en esta sección presentan la forma o sea. Esto se debe a que no registramos ningún caso en este corpus en el que o sea que exprese una RNP con sentido aclarativo-explicativo. Como veremos luego, esto puede deberse a la frecuente asociación de la conjunción que con la función de introducir una conclusión.

\subsection{Función aclarativo-explicativa: la reformulación parafrástica}

\section{O sea}

Por contraste con los 31 casos en los que o sea explica o aclara a través de una RNP, sólo encontramos 4 casos ( 1 en posición inicial y 3 en posición media) en los que este marcador lo hace a través de reformulaciones parafrásticas. El ejemplo 12 muestra el único caso en el que o sea aparece en posición inicial con esta función. Allí puede ser conmutado por es decir, ya que "las palabras" y "el arte" son aproximadamente equivalentes desde un punto de vista informativo (Marcos se refiere a la poesía y la escritura).

(12)Si hice algo:..: [de militancia], fue a través del cuerpo. Y a través de las palabras. $\mathbf{O}$ sea a través del arte.

En posición media, las apariciones de o sea como introductor de una RP no presentan sorpresas. En el ejemplo 13, pone en relación la expresión “todo el mundo” con una explicación en un registro más formal, pero informativamente equivalente ("el denominador común de la gente”). En el ejemplo 14, o sea introduce una explicación reformulativa según la cual "salir de la pobreza" equivale a "no tener que estar con lo poquito". Nótese que, en este caso, el sentido aclarativo es reforzado mediante la anteposición del marcador digamos -léxicamente cercano a es decir, que tanto en (13) como en (14) puede conmutarse por o sea. 


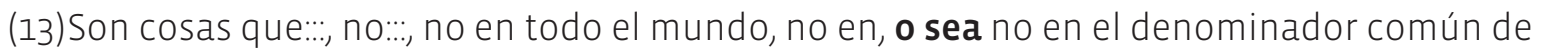
la gente lo ves.

(14)Yo quiero salir de la pobreza, digamos, o sea no// no tener que estar con, con lo poquito, o sea...

\section{O sea que}

El ejemplo 15 resulta especialmente interesante, ya que se trata del único caso en que la RP es expresada por o sea que (en posición inicial). Tras una interjección del investigador, Marcos introduce este marcador para retomar la idea previa a la interrupción y reformularla de modo inequívocamente parafrástico, sin añadir información nueva.

(15)MARCOS: Mi madre cuando, cuando yo era, cuando quedó embarazada de mí, obviamente estaba completamente convencida de que iba a ser un varón ¿no? (Ríe)

INVESTIGADOR: Ajá.

MARCOS: 0 sea que, en todo su embarazo, en su mente era un varón.

Podemos interpretar este uso particular de o sea que a partir de la propuesta de Rodríguez Ramalle (2014a; 2014b), quien plantea que diversos marcadores ilativos que incorporan la conjunción que (así que, conque, de manera que) "se pueden analizar como locuciones conjuntivas evidenciales, pues la causa de la que parten, si bien no necesita estar establecida necesariamente en el contexto, siempre aparece fijada en la fuente u origen de los conocimientos que posee el hablante: Io que ha oído, lo que ve, lo que le han dicho" (2014a: 239). La evidencialidad, como conjunto de mecanismos que marcan lingüísticamente las fuentes de la información, puede estar más o menos codificada gramaticalmente y abarca diversos tipos y grados (evidencia directa o indirecta, visual, escuchada por otros, inferida, etc.) (Aikhenvald, 2004; Haßler, 2009; Rodríguez Ramalle, 2014a). Si bien esta última autora se concentra en casos donde la evidencia proviene de situaciones extralingüísticas, esta también puede encontrarse inmediatamente antes en el mismo discurso ${ }^{21}$. Tal es el caso en el ejemplo 15, donde o sea que remite a lo dicho por el propio Marcos momentos antes. Respecto de así que, Rodríguez Ramalle dice que "puede ser una manera de comenzar o retomar un diálogo interrumpido, repitiendo algo que ya conocen los interlocutores" (2014a: 241), lo cual es igualmente válido para el uso de o sea que en el ejemplo 15. Allí, la repetición mentada por Rodríguez Ramalle adopta la forma de una reformulación parafrástica introducida por o sea que, donde que

21 Recordemos que Cubo de Severino dice que los reformuladores "Ilevan a inferencias retroactivas locales que buscan la fuente de información en el discurso previo" (2014: 348, énfasis añadido). 
añade en una misma operación la marca de evidencialidad intradiscursiva. Ilustramos este movimiento en el esquema 2.

\section{ESQUEMA 2}

Evidencialidad en un caso de reformulación parafrástica con o sea que

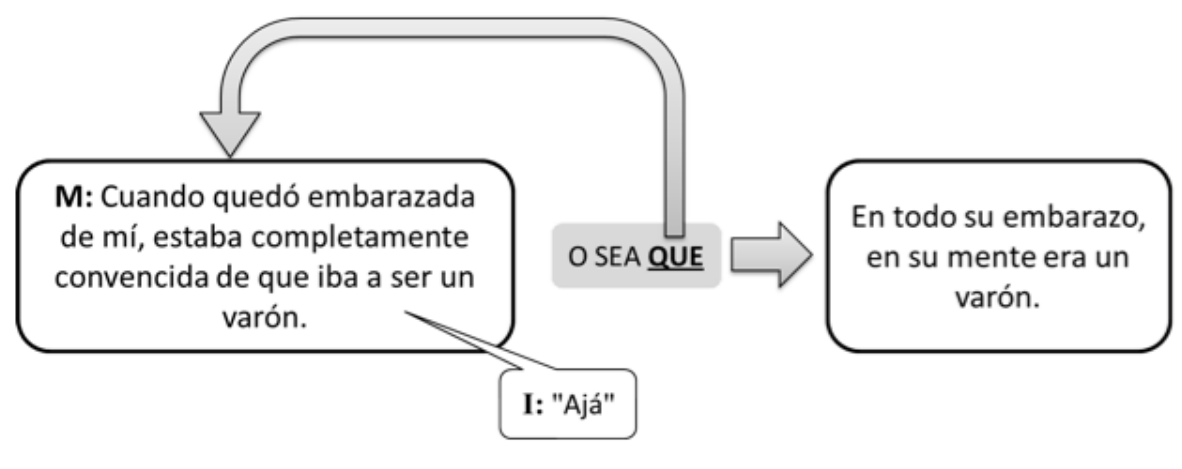

\subsection{Función conclusiva}

\section{O sea que}

En consonancia con los trabajos ya citados de Schwenter (1996), Casado Velarde (1991) y Murillo (2015), quienes señalan la asociación cercana entre la conjunción que y la introducción de una conclusión o consecuencia de lo dicho inmediatamente antes, encontramos que para la función conclusiva la cantidad de apariciones de la forma o sea que duplica a la de o sea (10 casos frente a 5). Este sentido conclusivo puede testearse mediante operaciones de paráfrasis con así que o por lo tanto. En el ejemplo 16, la paráfrasis permite ver claramente la relación no reformulativa de conclusión/consecuencia entre el hecho de que la anestesia perdiera su efecto en mitad de la operación y que ésta pueda ser evaluada por Marcos como "bastante complicada”. Dado que se trata de una relación de conclusión, no es posible en este caso realizar una paráfrasis de tipo "reflexivo" como la que aplicamos para probar la función aclarativo-explicativa en la subsección 3.1 (16”).

(16)La, la anestesia se fue, o sea que, fue como una operación bastante complicada (...).

$\left(16^{\prime}\right) \approx$ La, la anestesia se fue, así que / por lo tanto, fue como una operación bastante complicada (...).

(16”) La, la anestesia se fue. *Digo que la anestesia se fue porque fue como una operación bastante complicada (...).

En el ejemplo 17, por otra parte, se observa un "encadenamiento" de dos relaciones de conclusión/consecuencia: la primera, entre el hecho de que la vivienda de Marcos y su 
madre es de un ambiente y que vivir allí es "como vivir en un cuartito de dos por dos"; la segunda se da entre esto último y el hecho de "volverse loco". Esta segunda conclusión es introducida por el marcador es decir, que en co-ocurrencia con o sea que cobra aquí un valor conclusivo.

(17)Es [un departamento de] un ambiente, o sea que// realmente es como, vivir en un:: un cuartito de dos por dos, es decir, me vuelvo loco.

$\left(17^{\prime}\right) \approx$ Es [un departamento de] un ambiente, así que / por lo tanto// realmente es como, vivir en un:: un cuartito de dos por dos, es decir, me vuelvo loco.

O sea que también co-ocurre con así que en el ejemplo 18, donde encabeza la emisión. La relación de conclusión/consecuencia se da entre dos emisiones separadas por una intervención del investigador ${ }^{22}$. En la primera Marcos afirma, como vimos en el ejemplo anterior, que "se vuelve loco" al vivir con su madre en un departamento de un ambiente; y en la segunda concluye, a partir de esto, que evita frecuentar ese espacio.

(18)MARCOS: Es un ambiente, o sea que// realmente es como, vivir en un:: un cuartito de dos por dos, es decir, me vuelvo loco.

INVESTIGADOR: ¿Por acá es, ahora estás viviendo acá?

MARCOS: Sí, a dos cuadras sí. 0 sea que, trato de no estar mucho tiempo ahí así que, siempre estoy yendo de un lado para otro, de un lado para otro, aún aunque esté enfermo y:: agota.

$(18$ ) $\approx$ Sí, a dos cuadras sí. Así que / por lo tanto (como me vuelvo loco), trato de no estar mucho tiempo ahí así que, siempre estoy yendo de un lado para otro, de un lado para otro, aún aunque esté enfermo y:: agota.

En algunos casos, sin embargo, no resulta fácil desmarcar esta función conclusiva de otros sentidos posibles:

(19)Pero, desde muy chico era como, eh:: obviamente no me gustaba ni jugar con las muñecas ni utilizar vestidos, o sea que, siempre era preferible para mí ponerme un, utilizar un jardinerito que.:, o un pantalón de jogging, que un vestido.

22 También aquí, al igual que en (15), podemos interpretar o sea que como una "locución conjuntiva evidencial" que permite retomar un diálogo interrumpido a partir de información ya conocida (Rodríguez Ramalle, 2014a). Es por ello que, en la paráfrasis propuesta en (18”), reponemos parte de esa información entre paréntesis. 
(19’) obviamente no me gustaba ni jugar con las muñecas ni utilizar vestidos, así que / por lo tanto, siempre era preferible para mí ponerme un, utilizar un jardinerito que.:., o un pantalón de jogging, que un vestido.

(19") obviamente no me gustaba ni jugar con las muñecas ni utilizar vestidos, es decir que, siempre era preferible para mí ponerme un, utilizar un jardinerito que:.:, o un panta-lón de jogging, que un vestido.

En este ejemplo, o sea que puede interpretarse como un operador que introduce una consecuencia (dado que no le gustaba utilizar vestidos, entonces prefería utilizar un jardinero o un pantalón de jogging) (19’); pero también como un operador que introduce una reformulación explicativa de tipo no parafrástico (no le gustaba utilizar vestidos, en el sentido de que, por ejemplo, prefería utilizar un jardinero) (19”).

\section{0 sea}

Respecto del uso conclusivo de o sea, en 4 de los 5 casos encontrados este marcador aparece en posición media. En el ejemplo 20, o sea se inserta en un "encadenamiento" de inferencias iniciado por así que:

(20)Eh, con mi viejo siempre tuvimos como, muchas diferencias de pensamiento así que siempre, terminábamos peleando, un hombre muy, muy violento. Lo fue conmigo, lo fue con mis hermanos, o sea, no, no se modificó, no era solamente por mí o porque yo fuera trans.

Las peleas con el padre se justifican en primer lugar como una consecuencia de las mutuas diferencias de pensamiento. En un segundo momento, a partir del dato de que el padre era violento tanto con Marcos (que era trans) como con sus hermanos (que no lo eran), o sea permite introducir la conclusión de que la violencia paterna no respondía específicamente al hecho de que Marcos fuera trans.

En el ejemplo 21 o sea introduce una conclusión que, como indica el DPDE, va en un sentido diferente u opuesto a lo esperable (es decir, un argumento antiorientado):

(21)(...) el anestesista se desmayó en medio de la operación, o sea, digamos que la pude contar.

(21’) ₹ el anestesista se desmayó en medio de la operación, (pero) sin embargo, digamos que la pude contar.

Del hecho de que el anestesista se desmaye en medio de una operación cabría inferir que ésta tuvo resultados mortales o al menos catastróficos. O sea introduce un resultado contrario a esa expectativa, resultado que si bien no altera las connotaciones negativas de la experiencia 
relatada, permite realizar un giro: a pesar de haberse desmayado el anestesista, Marcos "la pudo contar" (está vivo, contando esta historia).

\subsection{Función restrictiva}

\section{O sea}

Esta función aparece en 8 casos, 4 de ellos en posición inicial y 4 en posición media. Llamamos a esta función "restrictiva” porque o sea aparece limitando, en mayor o menor grado, el alcance de lo dicho anteriormente o de sus consecuencias implícitas. Esta restricción retroactiva se asocia estrechamente a la clasificación de García Negroni de las formas de RNP. Así, en el ejemplo 22 o sea señala un distanciamiento respecto de lo que se viene afirmando -la búsqueda de un punto temporal preciso en el que Marcos habría "descubierto" su identidad de género - mediante la afirmación divergente de que, en realidad, "siempre" estuvo presente en él el juego de la androginia.

(22)MARCOS: Eh, y empecé a buscar, me, sobre todo por Internet, el acceso a Internet fue como una gran herramienta para, para empezar a descubrirme también a mí mismo.

INVESTIGADOR: ¿Cuando tenías 17, por ejemplo?

MARCOS: NO.

INVESTIGADOR: ${ }^{\circ}$ Después ${ }^{\circ}$

MARCOS: Mucho más. Sí, mucho más. 0 sea, siempre, estuvo en mí, el juego de la androginia.

$\left(22^{\prime}\right)$ Mucho más. Sí, mucho más. De cualquier modo/ en el fondo (aunque hablemos de un punto de partida), siempre, estuvo en mí, el juego de la androginia.

En el ejemplo 23, o sea marca un distanciamiento respecto de la afirmación "no soy una persona elevada" (en el sentido metafórico de ser profundo o inteligente). Por intermedio de o sea, Marcos mitiga esta primera afirmación argumentando en sentido contrario: aun no siendo una persona "elevada", intenta romper sus propios paradigmas mentales.

(23)(...) no soy una persona, elevada, digamos. $\mathbf{O}$ sea, intento tratar de, de romper con mis propios paradigmas, mis propias estructuras.

$\left(23^{\prime}\right) \approx(.$.$) no soy una persona, elevada, digamos. De todos modos/ al menos, intento tra-$ tarde, de romper con mis propios paradigmas, mis propias estructuras.

En el ejemplo 24, o sea señala en cambio la invalidación de lo dicho inmediatamente antes: al pedírsele un ejemplo de los prejuicios que afirma que le "quedaron" de su abuela, Marcos 
responde primero que no sabría decir de qué prejuicios se trata, para luego rectificarse y dar un ejemplo. En este caso, entonces, o sea invalida la afirmación "no sabría decirte ahora".

(24)INVESTIGADOR: ¿Qué, como qué prejuicios decís que te quedaron de tu abuela, o::?

MARCOS: Eh:.: Eh:., no sabría decirte ahora en este momento, qué prejuicios. 0 sea, a veces, a veces me sale, eh, no sé, cuando estás enojado y decís, a una mujer "puta de mierda" ¿entendés?

(24') ₹ Eh:.: no sabría decirte ahora en este momento, qué prejuicios. Bueno, no, a veces, a veces me sale, eh, no sé, cuando estás enojado y decís, a una mujer "puta de mierda" ¿entendés?

Los restantes usos restrictivos de o sea están relacionados con la reconsideración. En el ejemplo 25, el marcador permite reconsiderar la mención a una "parte femenina", asociada a lo sentimental y que otras personas estiman "perdida", e ir en un sentido diferente al afirmar que esa parte nunca fue dejada de lado.

(25) Siempre fui una persona sumamente sentimental, muy emocional, muy sensible. Que es algo que quizás, eh, muchas veces se, se lo asocia con mi parte femenina, o sea, nunca dejó, nunca dejé de lado mi parte femenina.

$\left(25^{\prime}\right) \approx$ Que es algo que quizás, eh, muchas veces se, se lo asocia con mi parte femenina, de hecho, nunca dejó, nunca dejé de lado mi parte femenina.

El ejemplo 26 es particularmente interesante, porque allí la reconsideración opera sobre una afirmación que fue adelantada e inmediatamente interrumpida por el propio hablante. Se trata de la idea "siempre jugué con la femineidad", preanunciada en la primera mención de "siempre" y explicitada recién al final de la emisión:

(26)Eh, [para mí es una opresión social] tener que:.: elegir, entre hombre o mujer. Obviamente, siempre, o sea mi imagen es una imagen, una imagen masculina, estoy del lado de la masculinidad pero, siempre, siempre jugué con la femineidad también.

$\left(26^{\prime}\right)$ O Obviamente, siempre, al fin y al cabo/ de hecho mi imagen es una imagen, una imagen masculina, estoy del lado de la masculinidad pero, siempre, siempre jugué con la femineidad también.

Lo que permite afirmar que la expresión "siempre jugué con la femineidad” está sujeta a reconsideración es su introducción posterior mediante el adversativo pero, que establece la oposición entre "haber jugado con la femineidad" y "proyectar una imagen masculina”. 
Si bien, como dijimos, estos usos de o sea están innegablemente emparentados con las operaciones de RNP, nos parece importante remarcar una característica que los distingue de la función aclarativo-explicativa abordada en la subsección 3.1. Ya mencionamos que, en su trabajo sobre la recategorización de verbos en marcadores, Company (2004) menciona la persistencia del significado referencial de los primeros en los segundos. Por otra parte, Schwenter (1996) habla de la conservación de rastros del sentido original de o sea en relación al carácter modal-epistémico del subjuntivo. Lo que nos interesa destacar aquí es la persistencia, en los usos de este marcador en nuestro corpus, del sentido original disyuntivo del conector o. En los ejemplos 22 a 26 (retomados a continuación en la tabla 3) proponemos que las informaciones articuladas por o sea pueden interpretarse de manera dicotómica, como presentando un cierto grado de oposición o de disyunción exclusiva. Retomamos así el énfasis que Espinosa Elorza (2010) y Casado Velarde (1996) otorgan a la disyunción al referirse al origen de o sea, aunque nuestra propuesta se aparta de la centralidad que ambos autores (especialmente Casado Velarde) le dan al sentido inclusivo de la disyunción ("una cosa, o la otra, o ambas") frente al sentido exclusivo ("o bien una cosa, o bien la otra, pero no ambas"). En casos como los que analizamos aquí, nos parece que la función pragmática de o sea retoma la disyunción original para limitar retroactivamente - con diferentes grados de intensidad, desde la cancelación hasta la inclusión sintética en una conclusión más amplia- el alcance del primer "polo" de la dicotomía en favor del segundo.

\section{TABLA 3}

Sentidos articulados disyuntivamente por o sea en su función restrictiva

\begin{tabular}{|c|c|c|c|}
\hline Ej. $n^{\circ}$ & 0 bien (A) & $\mathrm{O}$ bien (B) & $\begin{array}{l}\text { Función especifica de } \\
\text { o sea }\end{array}$ \\
\hline 22 & $\begin{array}{c}\text { El descubrimiento de la propia } \\
\text { identidad de género comenzó en } \\
\text { un momento puntual. }\end{array}$ & $\begin{array}{l}\text { El juego de la androginia } \\
\text { estuvo siempre. }\end{array}$ & $\begin{array}{l}\text { Distanciamiento de }(\mathrm{A}) \\
\text { para afirmar }(\mathrm{B})\end{array}$ \\
\hline 23 & No es una persona elevada. & $\begin{array}{c}\text { Es una persona que intenta } \\
\text { romper con sus propios } \\
\text { paradigmas. }\end{array}$ & $\begin{array}{l}\text { Distanciamiento de }(A) \\
\text { para matizar en }(B)\end{array}$ \\
\hline 24 & $\begin{array}{l}\text { No sabría decir a qué prejuicios } \\
\text { se refirió antes. }\end{array}$ & $\begin{array}{l}\text { Menciona un prejuicio en } \\
\text { concreto. }\end{array}$ & $\begin{array}{c}\text { Invalidación de }(A) \text { para } \\
\text { afirmar }(B)\end{array}$ \\
\hline 25 & $\begin{array}{l}\text { Su carácter sensible se asocia } \\
\text { con una parte femenina, } \\
\text { supuestamente dejada de lado. }\end{array}$ & $\begin{array}{c}\text { Nunca dejó de lado esa parte } \\
\text { femenina. }\end{array}$ & $\begin{array}{l}\text { Reconsideración de }(A) \\
\text { para corregir en }(B)\end{array}$ \\
\hline 26 & Siempre jugó con la femineidad. & Su imagen es masculina. & $\begin{array}{l}\text { Reconsideración de (A) } \\
\text { para afirmar (B) }\end{array}$ \\
\hline
\end{tabular}


Parece difícil reconstruir del mismo modo el sentido disyuntivo "original" en las otras funciones semántico-pragmáticas que analizamos, esto es, cuando o sea (que) expresa una explicación por RP (como en los ejemplos 14 y 15), una explicación por RNP (como en los ejemplos 1, 4 y 10) o una conclusión (como en el ejemplo 16). Quizá hallemos una clave para esa reconstrucción si consideramos el pasaje de un sentido exclusivo de la disyunción ("o bien una cosa o bien la otra, pero no ambas") a uno inclusivo ("una cosa o la otra, o ambas a la vez"). Casado Velarde considera que las reformulaciones en las que hay una equivalencia entre ambos términos pueden ser expresadas por o sea con el valor "O, en lugar de «X», sea «y»" (1991: 109). Esta explicitación del sentido de o sea realza un valor disyuntivo que no es necesariamente exclusivo. Frente a la función restrictiva de o sea, en la que los miembros relacionados no son compatibles entre sí, considerar el sentido inclusivo de la disyunción podría permitirnos rastrear la pervivencia del sentido "original" cuando o sea (que) expresa reformulaciones —en las que el segundo miembro no niega necesariamente al primero - y conclusiones —en las que el segundo miembro es distinto del primero, pero lo requiere.

\section{O sea que}

No registramos en el corpus casos en los que la forma o sea que aparezca cumpliendo una función restrictiva. La ausencia parece comprensible si tenemos en cuenta que esta función se encuentra estrechamente ligada a la RNP y que ésta, a su vez, no apareció en ningún caso asociada a la forma o sea que.

\subsection{Otros usos de o sea en posición inicial y media: continuación y refuerzo}

Siguiendo a Cortés Rodríguez, quien habla de "formas empleadas para amparar las vacilaciones expresivas de la lengua hablada” (1991: 62), Schwenter señala como un uso posible de o sea el servir como partícula de "relleno" (filler) o de hesitación, que "sostiene" la producción del discurso mientras el hablante organiza sus pensamientos (1996: 864). También López Serena y Loureda mencionan esta función de "apoyo para la construcción del discurso sobre la marcha” (2013: 238), y Cuenca (2003) señala la misma función de o sea como análoga del inglés I mean. En nuestro corpus encontramos tres casos — dos en posición inicial y uno en posición media - en los que o sea (sin que) cumple esta función continuativa. En efecto, en ninguno de ellos o sea conecta argumentos o informaciones diferentes, sino que precede o es precedido por alguna forma vocalizada de vacilación (señalada en cursiva en los ejemplos), superada la cual el hablante "retoma el hilo" del discurso:

(27)Internamente, psicológicamente, eh, hay cosas que no se modificaron [tras obtener el nuevo documento de identidad]. Eh:., o sea calculo que eso, algunos se lo preguntarán, 
otros no, por eso también hay muchas mujeres que, mujeres trans que ni siquiera quieren cambiar su documento, ni les interesa.

(28)Este:: bueno, viví con mi abuela::, hasta los 17 años. Que siempre, o sea::, este:: el nivel social que teníamos siempre fue, bastante pobre.

Por otra parte, encontramos un caso en el que o sea (sin que) se encuentra posicionado, no entre dos emisiones o cláusulas, sino entre los componentes de un sintagma nominal (en cursiva):

(29)INVESTIGADOR: Hasta los 17, estuviste así, ahí moviéndote.

MARCOS: Hasta ahora= (Ríe)

INVESTIGADOR: =Y después también digamos, claro. Con tu abuela también=

MARCOS: =Sí pero, hasta los 17, creo que con la persona sí, igual con la persona o sea más fija realmente, fue mi abuela.

Si bien los autores (Casado Velarde, 1991; Schwenter, 1996) mencionan la capacidad de los marcadores para aparecer virtualmente en cualquier parte del discurso, no encontramos análisis que se ocupen específicamente de o sea cuando aparece en este nivel sintáctico. Evidentemente, en el ejemplo 29 este marcador no cumple la función de relacionar dos argumentos; tampoco "conecta" el sustantivo persona con el superlativo la más fija. Podría considerarse pues que su función es continuativa, como en los ejemplos 27 y 28; sin embargo, dado que en este caso no aparece enmarcado por pausas ni vacilaciones, creemos que su función pragmática es la de reforzar el significado inmediatamente siguiente: (la) más fija. Dado que se trata de una aparición aislada, esta interpretación es forzosamente conjetural y no puede generalizarse.

\subsection{0 sea y o sea que en posición final: función atenuadora de cierre}

O sea y o sea que aparecen al final de la emisión en 9 casos, de los cuales 3 constituyen anacolutos. En los 6 restantes se trata de emisiones donde se relatan hechos o situaciones que, por su seriedad o gravedad, afectan de algún modo la imagen positiva del hablante. En estos casos, la función de o sea (que) es la de resguardar esta imagen positiva mediante un uso particular de la función conclusiva vista en la subsección 3.3. En efecto, en el cierre de la emisión o sea (que) insinúa una conclusión o consecuencia sumamente negativa que se desprendería de lo inmediatamente anterior, pero que permanece sin explicitar. Al dejar la elaboración y/o explicitación de esa conclusión a cargo del interlocutor, el hablante evita 
tener que explayarse (aún más) sobre situaciones cuyo conocimiento por parte del otro podría resultar algo incómodo o doloroso 23 . Algunos ejemplos de nuestro corpus son los siguientes:

(30)O sea que, hubo un riesgo de que si me pasaba algo ahí:.: [en la operación], lo cual PASÓ y gracias a Dios, este:.., sobreviví, ${ }^{\circ}$ sea․

(31)Así que realmente no:., no no, no puedo decir [de mi madre] más que, estoy bastante agradecido de que me, que me dé un espacio y un plato de comida, ${ }^{\circ} \mathbf{o} \mathbf{s e a}^{\circ}$.

(32)Y ahí pasamos momentos, muy muy heavies. Viví muy de cerca la prostitución, eh, pasamos hambre, nos han echado de lugares, ${ }^{\circ}$ o sea que ${ }^{\circ} \ldots$

En el ejemplo 30, la conclusión que afecta la imagen del hablante y que resulta mitigada es "yo podría haber muerto". En el ejemplo 31 se evoca una conclusión que afecta la imagen de un tercero: "no tengo casi nada bueno para decir sobre mi madre". En el ejemplo 32 la función "en suspenso" de o sea que parece involucrar al mismo tiempo la conclusión y la recapitulación: Io que se evita (volver a) decir es el balance global de una serie de circunstancias sumamente difíciles. Nótese que, en consonancia con el carácter polémico o incómodo de las conclusiones insinuadas, en los tres casos o sea (que) es pronunciado en un volumen bajo.

Como señalamos previamente (sección 1.3), tanto el DPDE como Schwenter (1996) mencionan esta función de protección de la imagen del hablante, y lo hacen remitiendo específicamente a la forma o sea (sin que). Por su parte, Briz sostiene que tanto o sea como o sea que pueden funcionar, cuando se ubican al final de la emisión, como "atenuantes por elisión de la conclusión": "en esta posición final (o hacia el final) cabe destacar también un uso frecuente de o sea (que) que deja en suspenso la conclusión. La elisión de ésta adquiere con frecuencia un efecto minimizador, más aún si la intervención es o conlleva una cierta polémica" (Briz, 2001: 310). Esto podría parecer en cierto modo extraño, toda vez que el sentido conclusivo, implícito en esta función atenuadora, es más claramente asociable a la forma con que. Sin embargo, hemos visto que también la forma sin que puede aparecer introduciendo una conclusión —en este caso se trata de una conclusión "elidida". Briz ofre-

23 En el DPDE se afirma que, especialmente en la lengua oral, o sea en posición final "adquiere un valor atenuador o minimizador de lo dicho o de lo que podría interpretarse de lo dicho. En otras palabras, evita responsabilidad sobre lo afirmado o deja en suspenso la intervención para que sea el interlocutor el que extraiga la explicación o las conclusiones oportunas" (Briz y otros, 2008). Sin embargo, en el ejemplo ofrecido el uso de o sea parece estar destinado a proteger la imagen del interlocutor antes que la del emisor: Yo no sé, la mayoría de tus preguntas, para mí, no son lógicas, o sea... 
ce ejemplos en los que, al igual que en nuestro corpus, la forma o sea cumple esta función atenuadora de cierre ${ }^{24}$.

Un último caso de o sea en posición final —en esta ocasión empleado por el investigador- involucra también la función conclusiva, pero con el fin de que el interlocutor brinde más información. Al dejar en suspenso el sentido conclusivo, el investigador invita a Marcos a completar el movimiento argumentativo con más información sobre qué significa para él "funcionar con amor":

(33)INVESTIGADOR: ¿Cómo es lo del amor? Me gustó lo del amor, que funcionás, con amor, o sea...

MARCOS: (Ríe) Soy una persona sumamente amorosa.

\section{Observaciones finales}

Para concluir, repasamos brevemente los resultados del análisis, realizando algunas observaciones generales sobre el marcador o sea (que) y sus usos. Es necesario recordar que estas conclusiones están limitadas a una pieza concreta de discurso oral en registro informal, producida en coordenadas determinadas por dos personas con un perfil social determinado. Por lo tanto, la comparación de estas observaciones con las de los autores citados, quienes trabajaron con corpus mucho más extensos, de diferentes registros y procedencias, sólo puede ser provisoria.

A partir de nuestro análisis, podemos señalar de modo general tres características del marcador discursivo o sea (que):

- Una alta frecuencia de aparición en la oralidad: 73 apariciones en 8.400 palabras, es decir, aproximadamente 1 aparición cada 115 palabras.

- Una gran plasticidad posicional: al comienzo, en el medio y al final de la emisión, así como también entre componentes internos.

24 "A: Mira yo te he contado todo lo que me pasaba con ellos/ tú lo sabes/ y sabes que mi relación con ellos no está todavía establecida/ y cómo-cómo-

B: Pero es que por lo que me estás diciendo no está establecida ninguna relación, ni tú con tus amigos, ni tu conmigo ni tú con nadie/ o sea".

Este ejemplo ha sido tomado de Briz (2001: 309), modificando ligeramente la transcripción. La conclusión negativa no explicitada por B sería: "No puedes establecer relaciones con nadie". 
- Una amplia variedad de funciones semántico-pragmáticas: seis funciones, aclarar/explicar, introducir una conclusión, restringir el alcance del miembro anterior, sostener la producción del discurso durante una vacilación, reforzar un significado y cerrar la emisión protegiendo la imagen del hablante, todas ellas registradas en un mismo texto.

Estas características ameritan las siguientes observaciones.

1. La versatilidad funcional de o sea (que) parece conservar y reflejar la gama de posibilidades semánticas propia del coordinante disyuntivo o. Este puede expresar, por ejemplo, una opción entre alternativas excluyentes (vivir o morir), un vínculo disyuntivo-copulativo (nos vemos esta semana o la siguiente) o una equivalencia (la mofeta o zorrino), mientras que entre dos numerales expresa un sentido de aproximación (había seis o siete personas). La prevalencia de la posición media de o sea (que) puede explicarse precisamente a partir del carácter coordinante de la disyunción, por el cual ésta tiende a ubicarse entre los constituyentes enlazados ${ }^{25}$. Por otra parte, en la subsección 3.4 observamos, a propósito de la función restrictiva, la pervivencia de un sentido exclusivo de la disyunción en la organización de la información. Nuestra primera observación apunta, entonces, a subrayar que hay varias razones por las que el sentido disyuntivo gramaticalizado en este marcador merece ser tenido en cuenta para su estudio y caracterización.

2. No obstante la prevalencia de la posición media, ninguna de las seis funciones relevadas apareció unívocamente ligada a una posición en particular. Solamente la función de proteger la imagen del hablante parece ser exclusiva de la posición final de la emisión. Conviene recordar, sin embargo, que esta función de o sea (que) puede considerarse como derivada de la función conclusiva, a la cual involucra implícitamente. Dado que la función conclusiva aparece tanto en la posición inicial como en la media, podemos concluir entonces, en un sentido amplio, que ninguna de estas funciones aparece confinada a una posición particular.

3. Hay un aspecto, empero, respecto del cual sí encontramos una distribución desigual de las funciones: se trata de la presencia o ausencia del elemento que (ver tabla 2). Mientras que o sea aparece ligado a las seis funciones encontradas, o sea que sólo aparece vinculado a tres de ellas: Ia conclusiva, la atenuadora de cierre y (en un solo caso) la aclarativo-explicativa por RP. Es decir que las funciones aclarativo-explicativa por RNP, restrictiva, continuativa y reforzadora no aparecen cuando que está presente. Esto confirma la observación de Schwenter: "A diferencia del amplio rango de relaciones semánticas que o sea puede establecer entre segmentos del discurso, investigaciones previas sobre o sea que han revelado un uso más especializado como marcador de conclusión del hablante o consecuencia” (1996: 863, traducción propia). 
La presencia de que, en efecto, parece "cerrar" el abanico de posibilidades de sentido, dejando la función conclusiva como prácticamente la única posible. Para la función aclarativo-explicativa por RNP, por ejemplo, constatamos 31 casos de o sea y ninguno de 0 sea que. Con la excepción del caso de RP analizado en el ejemplo 15, o sea que en posición inicial y media sólo cumple pues una función conclusiva ${ }^{26}$. La causa de esto puede buscarse en la estrecha relación entre la conjunción que y algunas formas de evidencialidad. Como señalamos antes siguiendo a Rodríguez Ramalle (2014a; 2014b), la evidencialidad mentada por que refiere en nuestros ejemplos a elementos discursivos previos. Es posible que, a partir de allí, se despliegue un sentido evidencial específicamente inferencial, que podemos ligar a o sea que en su función conclusiva. Pero entonces, ¿por qué o sea (sin que) puede asumir con éxito esta misma función? Una respuesta posible sería que, en estos usos de o sea, la reposición del que faltante con su matiz evidencial se deja a cargo del receptor/lector, tal como sucede con las conclusiones insinuadas en la función atenuadora de cierre.

4. Por último notamos que, en el caso de la función aclarativo-explicativa, las instancias de o sea que expresan reformulaciones de tipo no parafrástico exceden por mucho a aquellas en las que o sea (que) expresa una reformulación parafrástica (31 contra 6). Interpretamos esto como un reflejo de la polivalencia funcional de o sea, ya que la RNP comprende una mayor variedad de operaciones y manipulaciones del sentido entre dos partes del discurso (explicar lo que se acaba de decir o por qué se lo dijo, ejemplificar, reconsiderar, etc.) que las que se hallan en la simple equivalencia informativa.

Como veíamos al comienzo del trabajo, los marcadores del discurso se caracterizan por su plasticidad a la vez posicional y funcional. Nuestra hipótesis inicial, surgida del estudio preliminar del corpus, apuntaba a la especial relevancia que los operadores pragmáticos situados al comienzo de la emisión tendrían para guiar su interpretación. En el caso particular de o sea (que), el análisis nos permitió evidenciar una fuerte capacidad semántico-pragmática de orientación no sólo en la posición inicial, sino en todas las posiciones dentro de la emisión. La observación de esta versatilidad permite hacer más patente la ambigüedad interpretativa que da al discurso su dificultad y su riqueza.

\section{Bibliografía citada}

Aikhenvald, Alexandra, 2004: Evidentiality, Oxford: Oxford University Press.

26 En posición final, la función de atenuación se desprende de la conclusiva. 
Anscombre, Jean-Claude y Oswald Ducrot, 1983: La argumentación en la lengua, Madrid: Gredos.

Bello, Andrés, 2002 [1847]: Gramática: gramática de la lengua castellana destinada al uso de los americanos, Alicante: Biblioteca Virtual Miguel de Cervantes [disponible en: http://www. cervantesvirtual.com/obra/gramatica-gramatica-de-la-lengua-castellana-destinada-al-usode-los-americanos--0/].

Berkins, Lohana y Josefina Fernández (eds.), 2005: La gesta del nombre propio. Informe sobre la situación de la comunidad travesti en la Argentina, Buenos Aires: Ediciones Madres de Plaza de Mayo.

Briz, Antonio, 2001: “El uso de o sea en la conversación” en Josee De Kock (ed.): Lingüística con Corpus. Catorce aplicaciones sobre el español, Salamanca: Universidad de Salamanca, 287-318.

Briz, Antonio, Salvador Pons Bordería y José Portolés (coords.), 2008: Diccionario de partículas discursivas del español [disponible en: http://www.dpde.es/].

Casado Velarde, Manuel, 1991: "Los operadores discursivos es decir, esto es, o sea y a saber en español actual: valores de lengua y funciones textuales", Lingüística Española Actual, vol. XIII, 87-116.

Casado Velarde, Manuel, 1996: "Nota sobre la historia de los marcadores textuales de explicación es decir y o sea" en Manuel Casado Velarde y otros (eds.): Scripta Philologica in Memoriam Manuel Taboada Cid, volumen I, A Coruña: Universidade da Coruña, 321-328.

Company Company, Concepción, 2004: “¿Gramaticalización o desgramaticalización? Reanálisis y subjetivización de verbos como marcadores discursivos en la historia del español", Revista de filología española 1(84), 29-66.

Company Company, Concepción, 2014: "Principios teóricos vs. datos de corpus: ¿diálogo o enfrentamiento? Los adverbios en -mente como marcadores del discurso" en María Marta García Negroni (ed.): Marcadores del discurso. Perspectivas y contrastes, Buenos Aires: Santiago Arcos editor, 13-34.

Cortés Rodriguez, Luis, 1991: Sobre conectores, expletivos y muletillas en el español hablado, Málaga: Editorial Librería Ágora.

Cubo de Severino, Liliana, 2014: "Ordenadores y reformuladores en la interacción verbal de la defensa de tesis" en María Marta García Negroni (ed.): Marcadores del discurso. Perspectivas y contrastes, Buenos Aires: Santiago Arcos editor, 337-350.

Cuenca, Maria, 2003: "Two ways to reformulate: a contrastive analysis of reformulation markers”, Journal of Pragmatics 35, 1069-1093. 
Cuenca, Maria, 2013: "The fuzzy boundaries between discourse marking and modal marking” en Liesbeth Degand, Bert Cornillie y Paola Pietrandrea (eds.): Discourse Markers and Modal Particles. Categorization and description, Amsterdam/Philadelphia: John Benjamins, 191-216.

Degand, Liesbeth, Bert Cornillie y Paola Pietrandrea (eds.), 2013: Discourse Markers and Modal Particles. Categorization and description, Amsterdam/Philadelphia: John Benjamins.

Espinoza Elorza, Rosa María, 2010: Procesos de formación y cambio en las llamadas "palabras gramaticales", San Millán de la Cogolla: Cilengua.

FaIRCLough, Norman, 1992: Discourse and Social Change, Cambridge: Polity Press-Blackwell.

Fuentes Rodríguez, Catalina, 1993: “Conclusivos y reformulativos”, Verba 20, 171-198.

Fuentes Rodriguez, Catalina, 1996: La sintaxis de los relacionantes supraoracionales, Madrid: Arco Libros.

Garcés Gómez, María Pilar, 2008: La organización del discurso. Marcadores de ordenación y de reformulación, Madrid/ Frankfurt: Iberoamericana/ Vervuert.

Garcia Negroni, María Marta, 2009: "Reformulación parafrástica y no parafrástica y ethos discursivo en la escritura académica en español. Contrastes entre escritura experta y escritura universitaria avanzada”, Letras de Hoje 1(44), 46-56.

García Negroni, María Marta, 2014: "Presentación. Marcadores del discurso: perspectivas y contrastes" en María Marta García Negroni (ed.): Marcadores del discurso. Perspectivas y contrastes, Buenos Aires: Santiago Arcos editor, 5-10.

GüLICH, Elisabeth y Thomas KotsCHI, 1983: "Les marqueurs de la reformulation paraphrastique”, Cahiers de linguistique 5, 305-351.

HABLER, Gerda, 2009: "Modalidad, evidencialidad y deixis como componentes de la narratividad" en Gerda Haßler y Gesina Vokkamann (eds.): Deixis y modalidad en textos narrativos, Münster: Nodus Publikationen, 165-182.

Hernández Alonso, César, 1996 [1984]: Gramática funcional del español, tercera edición, Madrid: Gredos.

Ley de Identidad de Género No 26.743, 2012, en Boletín oficial de la República Argentina, No 32.404 (24 de mayo), Presidencia de la Nación [disponible en: https://www.boletinoficial.gob. ar/\#!DetalleNormaBusquedaAvanzada/10199860/null]. 
LINDE, Charlotte, 1993: Life Stories. The creation of coherence, Oxford: Oxford University Press.

López Serena, Araceli y Óscar Loureda Lamas, 2013: "La reformulación discursiva entre lo oral y lo escrito: una aproximación teórica y experimental”, Oralia 16, 221-258.

Martín Zorraquino, María Antonia, 2004: "El tratamiento lexicográfico de los marcadores del discurso y la enseñanza de E/LE” en Actas del XV Congreso Internacional de ASELE. Las Gramáticas y los Diccionarios en la Enseñanza del Español como Segunda Lengua, Sevilla: Deseo y Realidad, 53-67 [disponible en: http://cvc.cervantes.es/ensenanza/biblioteca_ele/asele/ pdf/15/15_0051.pdf].

Molinen, María, 2001: Diccionario de uso del español, versión electrónica 2.0 (CD-ROM), Madrid: Gredos.

Murillo, Silvia, 2015: "Sobre el uso de que con los marcadores de reformulación explicativa en español escrito” en Margarita Borreguero Zuloaga y Sonia Gómez-Jordana Ferary (eds.): Marqueurs du discours dans les langues romanes: une approche contrastive, Limoges: Lambert-Lucas, 168-179. Murillo, Silvia, 2009: “Los marcadores de reformulación explicativa en español y en inglés: estudio contrastivo de o sea y sus traducciones that is (to say) e in other words" en María Pilar Garcés Gómez (ed.): La reformulación del discurso en español en comparación con otras lenguas (catalán, francés, italiano, inglés, alemán e islandés), Madrid: BOE/Universidad Carlos III de Madrid, 137-161.

PARdo, María Laura, 2011: Teoría y metodología de la investigación lingüística. Método sincrónico-diacrónico de análisis lingüístico de textos, Buenos Aires: Tersites.

Pardo Abril, Neyla, 2007: Cómo hacer análisis crítico del discurso. Una perspectiva latinoamericana, Santiago de Chile: Frasis.

Pons Bordería, Salvador, 2014: "El siglo XX como diacronía: intuición y comprobación en el caso de o sea”, RILCE: Revista de filología hispánica 3(30), 985-1016.

Portolés, José, 2001 [1998]: Marcadores del discurso, segunda edición, Barcelona: Ariel.

Portolés, José, 2014: "Gramática, semántica y discurso en el estudio de los marcadores", en María Marta García Negroni (ed.): Marcadores del discurso. Perspectivas y contrastes, Buenos Aires: Santiago Arcos editor, 203-232.

Portolés, José y María Antonia Martín Zorraquino, 1999: “Los marcadores del discurso” en Ignacio Bosque y Violeta Demonte (coords.): Gramática descriptiva de la lengua española, vol. 3, Madrid: Espasa, 4051-4214. 
Real Academia Española (RAE) y Asociación de Academias de la Lengua Española (ASALE), 2010: Nueva gramática de la lengua española, Madrid: Espasa.

Rodriguez Ramalle, Teresa María, 2014a: "Sobre marcadores y su relación con la modalidad evidencial” en María Marta Garcia Negroni (ed.): Marcadores del discurso. Perspectivas y contrastes, Buenos Aires: Santiago Arcos editor, 233-250.

Rodriguez Ramalle, Teresa María, 2014b: “Una nueva reflexión en torno a los marcadores de reformulación con que”, Revista de Investigación Lingüística 17, 119-145.

SCHWENter, Scott, 1996: "Some reflections on o sea: A discourse marker in Spanish", Journal of Pragmatics 25, 855-874.

Traugott, Elizabeth, 2007: "Discussion article: Discourse markers, modal particles, and contrastive analysis, synchronic and diachronic", Catalan Journal of Linguistics 6, 139-157.

Urgelles-Coll, Miriam, 2010: The Syntax and Semantics of Discourse Markers, Londres: Continuum.

VAn Dıık, Teun, 1999: “El análisis crítico del discurso”, Anthropos (Barcelona) 186, 23-36. 